\title{
Terrestrial adaptation of green algae Klebsormidium and Zygnema (Charophyta) involves diversity in photosynthetic traits but not in $\mathrm{CO}_{2}$ acquisition
}

\author{
Mattia Pierangelini ${ }^{1}$ - David Ryšánek ${ }^{2,3} \cdot$ Ingeborg Lang $^{4} \cdot$ Wolfram Adlassnig ${ }^{4} \cdot$ \\ Andreas Holzinger ${ }^{1}$ (D)
}

Received: 2 June 2017 / Accepted: 9 July 2017/Published online: 18 July 2017

(c) The Author(s) 2017. This article is an open access publication

\begin{abstract}
Main conclusion The basal streptophyte Klebsormidium and the advanced Zygnema show adaptation to terrestrialization. Differences are found in photoprotection and resistance to short-term light changes, but not in $\mathrm{CO}_{2}$ acquisition.
\end{abstract}

Streptophyte green algae colonized land about 450-500 million years ago giving origin to terrestrial plants. We aim to understand how their physiological adaptations are linked to the ecological conditions (light, water and $\mathrm{CO}_{2}$ ) characterizing modern terrestrial habitats. A new Klebsormidium isolate from a strongly acidic environment of a former copper mine (Schwarzwand, Austria) is investigated, in comparison to Klebsormidium cf. flaccidum and Zygnema sp. We show that these genera possess different photosynthetic traits and water requirements. Particularly, the Klebsormidium species displayed a higher

Electronic supplementary material The online version of this article (doi:10.1007/s00425-017-2741-5) contains supplementary material, which is available to authorized users.

Andreas Holzinger

Andreas.Holzinger@uibk.ac.at

1 Department of Botany, Functional Plant Biology, University of Innsbruck, 6020 Innsbruck, Austria

2 Department of Botany, Faculty of Science, Charles University in Prague, Benátská 2, 12801 Prague 2, Czech Republic

3 Present Address: Laboratory of Environmental Microbiology, Institute of Microbiology of the CAS, v. v. i., Průmyslová 595, 25242 Vestec, Czech Republic

4 Faculty of Life Sciences, Core Facility Cell Imaging and Ultrastructure Research, University of Vienna, Althanstrasse 14, 1090 Vienna, Austria photoprotection capacity, concluded from non-photochemical quenching (NPQ) and higher tolerance to high light intensity than Zygnema. However, Klebsormidium suffered from photoinhibition when the light intensity in the environment increased rapidly, indicating that NPQ is involved in photoprotection against strong and stable irradiance. Klebsormidium was also highly resistant to cellular water loss (dehydration) under low light. On the other hand, exposure to relatively high light intensity during dehydration caused a harmful over-reduction of the electron transport chain, leading to PSII damages and impairing the ability to recover after rehydration. Thus, we suggest that dehydration is a selective force shaping the adaptation of this species towards low light. Contrary to the photosynthetic characteristics, the inorganic carbon $\left(\mathrm{C}_{i}\right)$ acquisition was equivalent between Klebsormidium and Zygnema. Despite their different habitats and restriction to hydro-terrestrial environment, the three organisms showed similar use of $\mathrm{CO}_{2}$ and $\mathrm{HCO}_{3}{ }^{-}$as source of $\mathrm{C}_{\mathrm{i}}$ for photosynthesis, pointing out a similar adaptation of their $\mathrm{CO}_{2}-$ concentrating mechanisms to terrestrial life.

Keywords Desiccation - Green algae - Light . Photosynthesis

\begin{tabular}{ll}
\multicolumn{2}{l}{ Abbreviations } \\
CEF-PSI & Cyclic electron flow around PSI \\
$\mathrm{C}_{\mathrm{i}}$ & Inorganic carbon \\
CCMs & $\mathrm{CO}_{2}$-concentrating mechanisms \\
ETC & Electron transport chain \\
LL & Low light \\
NPQ & Non-photochemical quenching \\
PQ & Plastoquinone \\
RLCs & Rapid light curves \\
SL & Saturating light
\end{tabular}




\section{Introduction}

Streptophyte green algae started land colonization about 450-500 million years ago (MYA) and this was an important step for the evolution of terrestrial plants (Becker and Marin 2009; Becker 2013). With the transition to land, ancestors of these organisms had to face new environmental conditions, including exposure to higher solar irradiance compared to the water environment, lower water accessibility and higher $\mathrm{pCO}_{2}$ than in the extant atmosphere (Becker and Marin 2009; Alboresi et al. 2010; Raven and Colmer 2016). Among streptophytes, Klebsormidium (Klebsormidiophyceae) and Zygnema (Zygnematophyceae) first appeared 500-700 MYA (Leliaert et al. 2011; Becker 2013) and they are classified as belonging to the basal and advanced groups of the streptophyte lineage, respectively (de Vries et al. 2016). The Klebsormidium genome has revealed that this organism acquired many genes specific for a plant terrestrial life (Hori et al. 2014; de Vries et al. 2017). Currently, Zygnema, as belonging to the order of Zygnematales, is among the closest algal relatives of land plants (Timme et al. 2012).

The pioneering behaviour of streptophyte green algae during land colonization is still present in modern habitats where they are abundant in freshwater, hydro-terrestrial habitats (Zygnema; Holzinger and Pichrtová 2016) and biological soil crusts (Klebsormidium; Holzinger and Karsten 2013; Karsten and Holzinger 2014) worldwide, and where they contribute to important ecological roles as primary production, carbon and nitrogen biogeochemical cycles, and soil stabilization (Elbert et al. 2012). Occurrence in these environments expose cells to various and extreme environmental conditions including long exposure to high light intensities and cellular water loss i.e., dehydration (Holzinger and Pichrtová 2016). Under such conditions, photosynthetic resistance against intense light involves the presence of photoprotective mechanisms e.g., energy dissipation as heat (non-photochemical quenching, NPQ; Alboresi et al. 2008; Gerotto et al. 2011; Goss and Lepetit 2015) and/or activation of a nonradiative electron recombination route to reduce ROS production (Ohad et al. 2010; Treves et al. 2016). Klebsormidium and Zygnema have been shown to have different NPQ kinetics that might confer a different sensitivity of their photosynthetic apparatus to high light environments (Gerotto and Morosinotto 2013).

As well as for light, not less important is photosynthetic resistance during dehydration (Heber 2008). In the case of Klebsormidium, transcriptomic analysis showed that dehydration caused up-regulation of genes involved in photosynthesis, showing that the photosynthetic apparatus is prone to acclimation under this condition (Holzinger et al. 2014). However, in nature, dehydration may occur rapidly, without giving time for the transcripts to be translated into proteins and to the cell, the chance to acclimate (Cruz de Carvalho et al. 2014). Moreover, due to the variability of light climate (e.g., daily light changes), frequently dehydration occurs under elevated irradiances which might pose a danger for photosynthesis (Gray et al. 2007; Raanan et al. 2016a). Consequently, high desiccation tolerant species must possess constitutively expressed mechanisms to quickly protect the photosynthetic apparatus and allowing recovery when water is taken up again (Gray et al. 2007; Yamakawa et al. 2012; Bar-Eyal et al. 2015). It is known that Klebsormidium is capable to inactivate photosynthesis during dehydration in low light (40 $\mu$ mol photons $\mathrm{m}^{-2} \mathrm{~s}^{-1}$ ) and recover after rehydration (Herburger and Holzinger 2015; Karsten et al. 2016). However, to better understand its physiological requirements and distribution in the environment, we need to understand the response of its photosynthetic apparatus to dehydration when exposed to different light intensities.

Upon land colonization, besides high light and dehydration tolerance, adaptations for resources acquisition such as inorganic carbon $\left(\mathrm{C}_{\mathrm{i}}\right)$ are essential to guarantee the species occurrence in a certain environment. $C_{i}$ acquisition has been extensively studied in aquatic algae and many of them are known to possess $\mathrm{CO}_{2}$-concentrating mechanisms (CCMs) i.e., structural and functional components whose role is to furnish the cell with $\mathrm{CO}_{2}$ for photosynthesis (Giordano et al. 2005; Reinfelder 2011). Different CCMs are observed among different species, in relation to the form of $\mathrm{C}_{\mathrm{i}}$ uptaken $\left(\mathrm{CO}_{2}\right.$ vs $\left.\mathrm{HCO}_{3}{ }^{-}\right)$and presence or absence of pyrenoids (Ratti et al. 2007; Brading et al. 2013; Stojkovic et al. 2013). In several streptophyte green algae, including Klebsormidium and Zygnema, functional CCMs can be inferred from the presence of pyrenoids (Meyer et al. 2008; Herburger et al. 2015; Mikhailyuk et al. 2015), an organelle which, although with some exceptions, is often associated with intracellular $\mathrm{C}_{\mathrm{i}}$ accumulation and CCM (Smith and Griffiths 1996; Maberly et al. 2009; Villarreal and Renner 2012; Raven et al. 2017). In the case of Zygnema, active CCM are also indicated by low $\mathrm{CO}_{2}$ compensation point (Birmingham and Colman 1979). In relation to the preferred $\mathrm{C}_{\mathrm{i}}$ forms, the evolutionary adaptation of these organisms to terrestrial conditions may have favoured their predilection for $\mathrm{CO}_{2}$ acquisition rather than $\mathrm{HCO}_{3}{ }^{-}$. Yet, different preferences for $\mathrm{CO}_{2}$ or $\mathrm{HCO}_{3}{ }^{-}$may be expected in relation to single species adaptation to a particular habitat (Lachmann et al. 2016). For instance, in species such as Zygnema with higher restriction to moist environments (Herburger and Holzinger 2015; Lajos et al. 2016), where both $\mathrm{CO}_{2}$ and $\mathrm{HCO}_{3}{ }^{-}$are present, lower dependence on $\mathrm{CO}_{2}$ can be expected. Contrary, for species with higher adaptation to soil or dry conditions as Klebsormidium, $\mathrm{CO}_{2}$ could represent the preferred source of $\mathrm{C}_{\mathrm{i}}$ for photosynthesis. However, to our knowledge, the 
mechanisms whereby these terrestrial streptophyte green algae attain $C_{i}$ have not been investigated so far.

The aim of the present study is to perform a comparison of physiological traits in the genera Klebsormidium and Zygnema in relation to ecological parameters (light, water and $\mathrm{C}_{\mathrm{i}}$ ) which characterize terrestrial habitats. For our experiments, we compared a new Klebsormidium isolate from an acidic environment with $K$. cf. flaccidum from a soil crust and a Zygnema sp. isolated from a sandy river shore. The latter two isolates have been characterized by means of phylogeny, structure and ultrastructure as well as some physiological aspects before (Karsten et al. 2013; Mikhailyuk et al. 2015; Herburger et al. 2015). These previous observations gave a solid basis for the present study; however, a direct comparison of these two genera in culture medium at the same culture age and with the same methods was not carried out before. We analysed their ability to employ photoprotective mechanisms and how they are linked to terrestrial light conditions. We also characterized the changes of the photosynthetic apparatus during a dehydration/rehydration cycle under different light regimes, aiming to define the role of dehydration in shaping species-specific photosynthesis. Finally, we assessed the presence of CCMs and tested if the acquisition of different $\mathrm{C}_{\mathrm{i}}$ forms is related to the occurrence of these genera in different habitats.

\section{Materials and methods}

\section{Species morphology and isolation}

We used a Zygnema sp. (Culture collection of Algae Göttingen, SAG 2419, isolated from a sandy river shore, Herburger et al. 2015) and two Klebsormidium isolates. These included: (1) a new Klebsormidium isolate with long, tangled filaments, collected from the acidic ( $\mathrm{pH} 4.3)$ environment of a former mining site termed Schwarzwand $\left(47^{\circ} 9^{\prime} 36.84^{\prime \prime} \mathrm{N}, 13^{\circ} 13^{\prime} 13.28^{\prime \prime} \mathrm{E}\right)$ (Großarl Valley in Salzburg, Austria, Adlassnig et al. 2013); and (2) the previously described $K$. flaccidum KUE1 (alpine biological soil crust, Tyrolean Alps, Austria) and grouping into the B-Clade according to ITS-phylogeny (Karsten et al. 2013). The latter species name was also modified into $K$. cf. flaccidum by Mikhailyuk et al. (2015) according to the observation that the filaments had a stronger tendency to disintegrate.

\section{Culture conditions}

The two Klebsormidium isolates were grown in modified Bolds Basal Medium (MBBM) and Zygnema in standard BBM culture media, respectively, and buffered at $\mathrm{pH} 7.5$ using $40 \mathrm{mmol} \mathrm{L}{ }^{-1}$ Hepes. Cultures were incubated in a growth chamber with a temperature cycle of $20-15{ }^{\circ} \mathrm{C}$ of $16: 8 \mathrm{~h}$, and exposed to an incident photon flux density of 50-70 $\mu \mathrm{mol}$ photons $\mathrm{m}^{-2} \mathrm{~s}^{-1}$. All species were maintained in batch growth, using $200 \mathrm{~mL}$ Erlenmeyer flasks filled with a maximal culture volume of $100 \mathrm{~mL}$. Cultures were refreshed with culture medium regularly (every 2 weeks) to maintain filaments concentration low and to avoid nutrients depletion in the medium. To test a possible/particular adaptation of Klebsormidium isolated from Schwarzwand to low $\mathrm{pH}$ environments, results from control experimental condition $(\mathrm{pH}$ 7.5) were compared to analyses performed on filaments transferred for $24 \mathrm{~h}$ into a MBBM pH 4.1 (buffered with $5 \mathrm{mM}$ citric acid/Na-citrate, Gerloff-Elias et al. 2005). Prolonged (several days) exposure of filaments to low $\mathrm{pH}$ caused the culture medium to get 'turbid' which we considered unsuitable for further physiological experiments.

\section{Phylogenetic analyses}

The new Klebsormidium strain from Schwarzwand was characterized by $r b c \mathrm{~L}$ (large subunit of ribulose-1,5-bisphosphate carboxylase/oxygenase) marker, which is the most used molecular marker for this streptophytic green algae. The DNA from the strain was isolated according to the protocol of Ryšnek et al. (2015). The sequences of the $r b c \mathrm{~L}$ gene were obtained using polymerase chain reaction (PCR) amplification with a Touchgene Gradient cycler (Techne, Cambridge, UK). The $r b c \mathrm{~L}$ gene was amplified using the forward primer KF590 150 (5'-GAT GAA AAC GTA AAC TCT CAG C- $3^{\prime}$ ) and the reverse primer $r b c \mathrm{~L}$ KR2 (5'-GGT TGC CTT CGC GAG CTA-3') ('̌kkaloud and Rindi 2013). Each $20 \mu \mathrm{L}$ reaction solution for PCR was conducted as described by Ryšánek et al. (2015). The PCR protocol followed that of Škaloud and Rindi (2013). Sequencing reads were assembled and edited using SeqAssem software (Hepperle 2004). Newly obtained Klebsormidium $r b c \mathrm{~L}$ sequence and the sequences available in the GenBank database were used to produce an alignment for phylogenetic analyses. The final alignment was constructed by ClustalW (Thompson et al. 1994) with MEGA v6.06 (Tamura et al. 2011). The aligned data set was analysed using Bayesian analysis (BI) with MrBayes v3.1.2 (Huelsenbeck and Ronquist 2001), maximum likelihood analysis (ML) with GARLI (Zwickl 2006), and maximum parsimony (MP) analysis with PAUP v4.0b10 (Swofford 2002). The evolutionary model used was the same as in Ryšánek et al. (2015). The BI analysis was performed using the priors set as default in MrBayes; the robustness of the tree topologies was assessed by bootstrapping the data set as described by Škaloud and Rindi (2013). 


\section{Light- and transmission electron microscopy (TEM)}

For light microscopy a Zeiss Axiovert $200 \mathrm{M}$ microscope with a $100 \times 1.3$ NA objective lense was used and transmission electron microscopy was essentially carried out by a classical chemical fixation procedure as previously described (Holzinger et al. 2009). Transmission electron micrographs were captured with a TRS $2 \mathrm{k}$ SSCCD camera connected to a Zeiss Libra 120 TEM operated at $80 \mathrm{kV}$.

\section{Rapid light curves, NPQ and OJIP measurements}

The light acclimation status and PSII properties of Klebsormidium and Zygnema were analyzed using a PAM 2500 fluorimeter (Heinz Walz, Effeltrich, Germany). Prior any measurements, samples were dark acclimated for $15 \mathrm{~min}$. Rapid light curves (RLCs), as assessment of the photosynthetic response to rapid increase of light (every $30 \mathrm{~s}$ ), were obtained by exposing cells to light intensities between 0 and $2014 \mu \mathrm{mol}$ photons $\mathrm{m}^{-2} \mathrm{~s}^{-1}$. The RLCs were then fitted through the mathematical model of Walsby (1997). Fluorescence induction curves for NPQ estimation were obtained using 20 saturating light pulses $(300 \mathrm{~ms})$ upon cells exposed to an actinic light intensity of $1159 \mu \mathrm{mol}$ photons $\mathrm{m}^{-2} \mathrm{~s}^{-1}$, and followed by a dark recovery time to monitor NPQ relaxation phase. The OJIP $(\mathrm{O}$, origin; $\mathrm{J}$ and I, intermediated inflections; P, peak; Stirbet et al. 2014) transients were obtained by a multi turn-over flash generated using the default trigger pattern of PamWin-3 software (Poly300 ms.FTM).

\section{$P$ vs $I$ curves}

Rates of photosynthetic $\mathrm{O}_{2}$ evolution as a function of irradiance ( $P$ vs $I$ curve) were used as assessment of photosynthetic response towards relatively slower increase of light intensity. The $P$ vs $I$ curves were measured with a Presens Fibox 3 oxygen optode (Presens, Regensburg, Germany) fixed in a 3-mL thermostatic acrylic chamber (type DW1, Hansatech Instruments, Norfolk, UK) as in Kaplan et al. (2013). Prior each $P$ vs $I$ curve measurement, the cells were dark acclimated for 15 min with the final 5 min of this incubation period used to measure the dark respiration $\left(R_{\mathrm{d}}\right)$. Following the dark period, $P$ vs $I$ curves were obtained by exposing the cell suspension to a progressive increase (every 5-10 min) of light intensities between 0 and $1520 \mu \mathrm{mol}$ photons $\mathrm{m}^{-2} \mathrm{~s}^{-1}$. To avoid the possibility of photorespiration, during the experiments the $\mathrm{O}_{2}$ concentration in the chamber was maintained between 15 and $60 \%$ of air equilibrium (Pierangelini et al. 2014). The $P$ vs $I$ curves and photosynthetic parameters as maximum photosynthetic rate $\left(P_{\max }\right)$, light harvesting $(\alpha)$, photoinhibition $(\beta)$ and onset of light saturated photosynthesis $\left(I_{k}=P_{\max } / \alpha\right)$ were generated using the model of Walsby (1997). Results were normalized to Chl $a$. At the end of each $P$ vs $I$ curve, the algal suspension was filtered onto a Whatman GF/C glass microfiber filter, resuspended in $1 \mathrm{~mL}$ DMF (with overnight extraction), and the Chl $a$ quantified photometrically using the equations of Porra et al. (1989).

\section{Dehydration and recovery experiment}

To study the response of the photosynthetic apparatus when dehydration occurs at both sub- and saturating light intensity for photosynthesis, we performed a dehydration/ rehydration experiment at two light regimes, 25 (LL, low light) and 185 (SL, saturating light) $\mu \mathrm{mol}$ photons $\mathrm{m}^{-2} \mathrm{~s}^{-1}$; measured with a Solar Light PMA 2132 cosine corrected PAR sensor connected to a Solar Light PMA 2100 radiometer (Solar Light Co., Inc., Philadelphia, PA, USA). Samples were placed under the same light source and the low light treatment was obtained using light screens. The dehydration and rehydration cycle were performed essentially as in Karsten et al. $(2014,2016)$ and in Herburger et al. (2015). Filaments of Klebsormidium and Zygnema were collected from the culture, re-suspend in $200 \mu \mathrm{L}$ of fresh MBBM or BBM media and placed onto a $45-\mathrm{mm}$ membrane filter (mixed cellulose ester, Whatman $\mathrm{GmbH}$, Dassel, Germany). Filters were placed inside the desiccation chamber described in Karsten et al. (2014), and filled with $100 \mathrm{~mL} 3.5 \mathrm{~mol} \mathrm{~L}^{-1} \mathrm{KCl}$ dehydrating solution. Dehydration was allowed to take place for $24 \mathrm{~h}$. After this period, filaments on filters were rewetted with $200 \mu \mathrm{L}$ of fresh culture medium and the $\mathrm{KCl}$ solution in the chamber replaced with $100 \mathrm{~mL}$ of tap water. The relative humidity (78.5-94\%) during the experiment was recorded using a PCE-MSR145S-TH mini data logger (PCE Instruments, Meschede, Germany). For the assessment of the PSII proprieties, the PAM 2500 probe was placed outside the chamber at the fixed distance of $11 \mathrm{~mm}$ from the filter. The effective quantum yield ( $\left.\mathrm{YII}=\left(F_{m}^{\prime}-F\right) / F_{m}^{\prime}\right)$ was measured on filaments exposed to each respective light intensity. $F_{\mathrm{v}} / F_{\mathrm{m}}$ and OJIP transients were measured during the dehydration phase on dark acclimated filaments for $15 \mathrm{~min}$. At the end of the rehydration phase of Klebsormidium, $F_{\mathrm{v}} /$ $F_{\mathrm{m}}$ were measured on filaments collected from the filters and resuspended in fresh MBBM medium.

\section{pH drift and $\mathrm{C}_{\mathrm{i}}$ acquisition}

For the analysis of $\mathrm{C}_{\mathrm{i}}$ acquisition in Klebsormidium and Zygnema we performed a pH-drift experiment as described by Maberly and Spence (1983) using an artificial assay 
medium ( $\mathrm{pH} 7.5$, alkalinity $\sim 1 \mathrm{mEq} \mathrm{L}^{-1}$ ) prepared as in Lachmann et al. (2016). Filaments were harvested from the culture, washed in $20 \mathrm{~mL}$ of assay medium, placed in an air tight $25 \mathrm{~mL}$ glass vial (obtaining a $\mathrm{Chl} a$ concentration between 0.4 and $0.8 \mu \mathrm{g} \mathrm{mL}^{-1}$ ), and exposed to a maximal incident light intensity of $110 \mu \mathrm{mol}$ photons $\mathrm{m}^{-2} \mathrm{~s}^{-1}$. The increase of $\mathrm{pH}$ of the assay medium was recorded every $30-60$ min by quickly opening and introducing the $\mathrm{pH}$ probe into the vials. During the measures gas exchange was minimal since the $\mathrm{pH}$ probe fitted the vials aperture. At the end of $\mathrm{pH}$ drift incubation, the final alkalinity of assay medium was measured by Gran tritration and $\mathrm{C}_{\mathrm{i}}$ speciation $\left(\mathrm{CO}_{2}, \mathrm{HCO}_{3}^{-}, \mathrm{CO}_{3}^{-2}\right)$ calculated from the constants of Millero (1979) and the NBS pH scale, using the $\mathrm{CO}_{2}$ Sys.xls application (Holland et al. 2012). The results were used to estimate the variation of the $\mathrm{C}_{\mathrm{i}}$ forms during the course of the experiment, to calculate the maximal $\mathrm{C}_{\mathrm{i}}$ uptake rate normalized to $\mathrm{Chl} a$ (extracted as described above), and calculate the quotient of final total $\mathrm{C}_{\mathrm{i}}\left(C_{\mathrm{T}}\right)$ over final alkalinity $\left(C_{\mathrm{T}} / \mathrm{Alk}\right.$, Lachmann et al. 2016).

\section{Statistical analysis}

Experiments were performed with at least three biological replicates. We tested the significance of mean differences among the three organisms using one-way ANOVA followed by Bonferroni's multiple comparison test. The variation among means in relation to time was tested using two-way repeated-measures (RM) ANOVA. Comparison between two means was carried out by two-tailed $t$ test. The analyses were performed using the software GraphPad Prism 5, setting the threshold of significance at $95 \%$.

\section{Results}

\section{Phylogenetic characterization, light and transmission electron microscopy of the new isolate}

While phylogenetic and morphological characterization of the $K$. cf. flaccidum strain KUE1 (Karsten et al. 2013; Mikhailyuk et al. 2015) and Zygnema sp. (SAG 2419, Herburger et al. 2015) were previously available, the new strain isolated from Schwarzwand, Austria, hereafter Klebsormidium sp. (SCHW), was found to group into clade E2 by $r b c$ L analysis (Fig. 1). The cells had an average cell width of $5.5( \pm 0.5) \mu \mathrm{m}$ and an average cell length of 9.3 $( \pm 1.8) \mu \mathrm{m}$, and a parietal chloroplast with a prominent pyrenoid surrounded by numerous starch grains (Fig. 2). The chloroplasts covered at least $2 / 3$ of the inner cell surface. Transmission electron microscopy of the new isolate allowed to further characterize the subcellular organization. The chloroplasts contained prominent pyrenoids (Fig. 3) that were transversed by thylakoid membranes (Fig. 3a). Several pyrenoids were found to be surrounded by starch grains (Fig. 3). The chloroplasts contained several plastoglobules (Fig. 3a, b). The nucleus was found occasionally not in the typical central position, but close to the cross walls, sometimes drastically elongated (Fig. 3a, b).

\section{Maximum quantum yield and Non-photochemical quenching}

Similar $F_{\mathrm{v}} / F_{\mathrm{m}}$ were found among Klebsormidium isolates and Zygnema $(P=0.1746$, Table 1$)$. The different NPQ kinetics between Klebsormidium and Zygnema are reported in Fig. 4. Compared to Zygnema, both Klebsormidium isolates showed a higher capacity to perform NPQ. Moreover, differently from Zygnema, the Klebsormidium NPQ was inducible and reaching full activation after a relative long time $(\sim 6 \mathrm{~min})$ of exposure to strong actinic light. Klebsormidium sp. (SCHW) showed higher maximal NPQ $(P=0.0107)$ than $K$. cf. flaccidum (KUE1). The kinetics of the Klebsormidium NPQ induction reported here are comparable to the results of Gerotto and Morosinotto (2013).

\section{Slow vs rapid increase of light}

To understand how the NPQ traits are linked to natural light conditions, we compared the results of $P$ vs $I$ curves with the RLCs. The results of $P$ vs $I$ curves, showing the photosynthetic responses of Klebsormidium isolates and Zygnema to relatively slow increase of light intensity, are reported in Fig. 5a-c and in Table 1. $R_{\mathrm{d}}(P=0.3731)$ and $P_{\max }(P=0.9023)$ were similar among the Klebsormidium isolates and Zygnema. The $\alpha$ was higher for Klebsormidium sp. (SCHW) than in K. cf. flaccidum (KUE1) and Zygnema $(P=0.0155)$. Reflecting the higher $\alpha$, the $I_{k}$ was found lower in Klebsormidium sp. (SCHW) $(P=0.0137)$. Klebsormidium sp. (SCHW) showed negligible $\beta$, whereas for $K$. cf. flaccidum (KUE1) $\beta$ was null. On the other hand, although statistically weak $(P=0.0574)$, Zygnema showed higher tendency to photoinhibition. Figure $5 \mathrm{~d}-\mathrm{f}$ show the responses of Klebsormidium isolates and Zygnema to a comparatively faster increase of light intensity (RLCs curves). The most striking observation is that with RLCs all species studied had higher susceptibility to high light intensity $(\beta)$ than during the $P$ vs $I$ curves.

\section{Low pH experiment}

Short-term exposure (24 h) of Klebsormidium sp. (SCHW) to $\mathrm{pH} 4.1$ caused a decline of the $F_{\mathrm{v}} / F_{\mathrm{m}}$ from $0.67( \pm 0.02)$ 


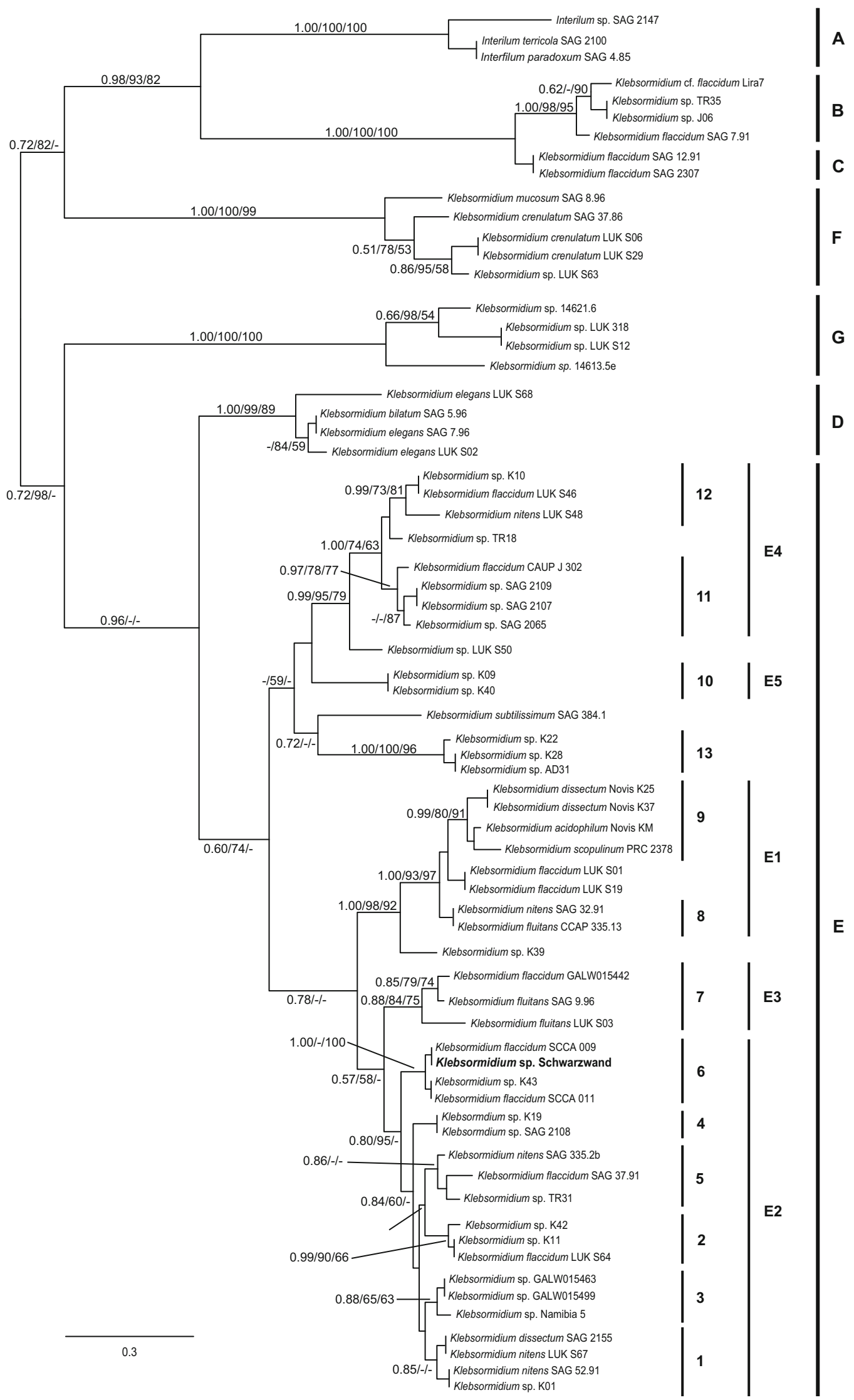


4Fig. 1 Phylogenetic tree obtained from Bayesian analysis based on $r b c \mathrm{~L}$ dataset, showing the position of newly investigated strain of Klebsormidium sp. isolated from Schwarzwand and their relatives. Values at the nodes indicate statistical support estimated by MrBayes posterior probabilities (left), maximum likelihood bootstrap (middle), and maximum parsimony bootstrap (right). The clade numbering $(A-$ $G, E 1-E 6)$ follows Rindi et al. (2011) and clades (1-13) are according to Škaloud and Rindi (2013)
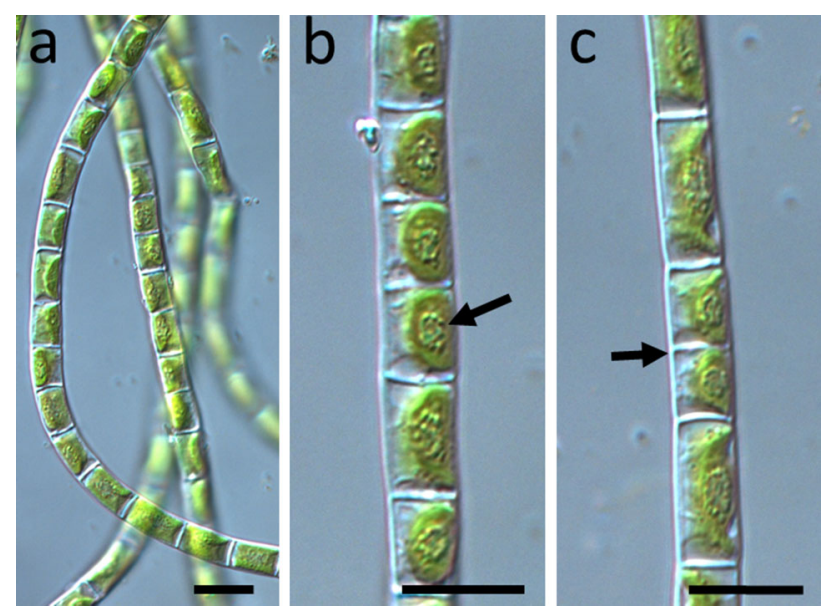

Fig. 2 Light micrographs of Klebsormidium sp. (SCHW). a Overview of several filaments showing how they are among each other. b Detail of one filament showing the prominent pyrenoids (arrow) in the centre of the chloroplasts, $\mathbf{c}$ filament with cells that just divided (arrow), illustrating the different cell lengths. Bars $10 \mu \mathrm{m}$ down to $0.51( \pm 0.03) \quad(P=0.0019)$, suggesting the occurrence of changes/damages at the PSII. The RLCs (Fig. 5d) highlighted a decline of $\alpha(P=0.0134)$ but $\mathrm{rETR}_{\max }$ was not altered under the low $\mathrm{pH}$ condition $(P=0.5671)$.

\section{Dehydration and rehydration}

As reported by Herburger and Holzinger (2015) Zygnema was more sensitive to dehydration than Klebsormidium. The YII rapidly declined during dehydration and did no recover after $24 \mathrm{~h}$ (Fig. S1). Contrary, Klebsormidium sp. (SCHW) tolerated longer dehydration periods and quickly recovered even after $24 \mathrm{~h}$ of being in a dehydrated state (Fig. 6). Due to the dependence of the YII on the light acclimated state (which induces non-photochemical downregulation and reaction centres closure), the absolute differences in YII between the LL and SL treatments can be attributed to the different light regime at which the cells were exposed during the fluorescence measures. Yet, our results showed that the capacity of Klebsormidium to tolerate dehydration and rehydration cycle was influenced by the light exposure. During dehydration, the YII (Fig. 6a) of cells exposed to SL started to drop down to null values earlier (40 min) than for cells under the LL treatment. In SL, the $F_{\mathrm{o}}$ measured on dark acclimated cells was higher than in cells under LL (two-way ANOVA RM,
Fig. 3 Transmission electron micrographs illustrating Klebsormidium sp. (SCHW). a Overview with parietal chloroplast that contains a central pyrenoid. Towards the edges of the cell, larger vacuoles are found, note the position of the nucleus in the upper cell. b Cell with elongated nucleus, positioned close to the cross wall, several plastoglobues can be found. c Detail of the chloroplast showing pyrenoids surrounded by starch grains and crossed by thylakoids. $C h l$ chloroplast, $C W$ cell wall, $N$ nucleus, $P G$ plastoglobules, $P y$ pyrenoid, $S$ starch grain. Bars $1 \mu \mathrm{m}$
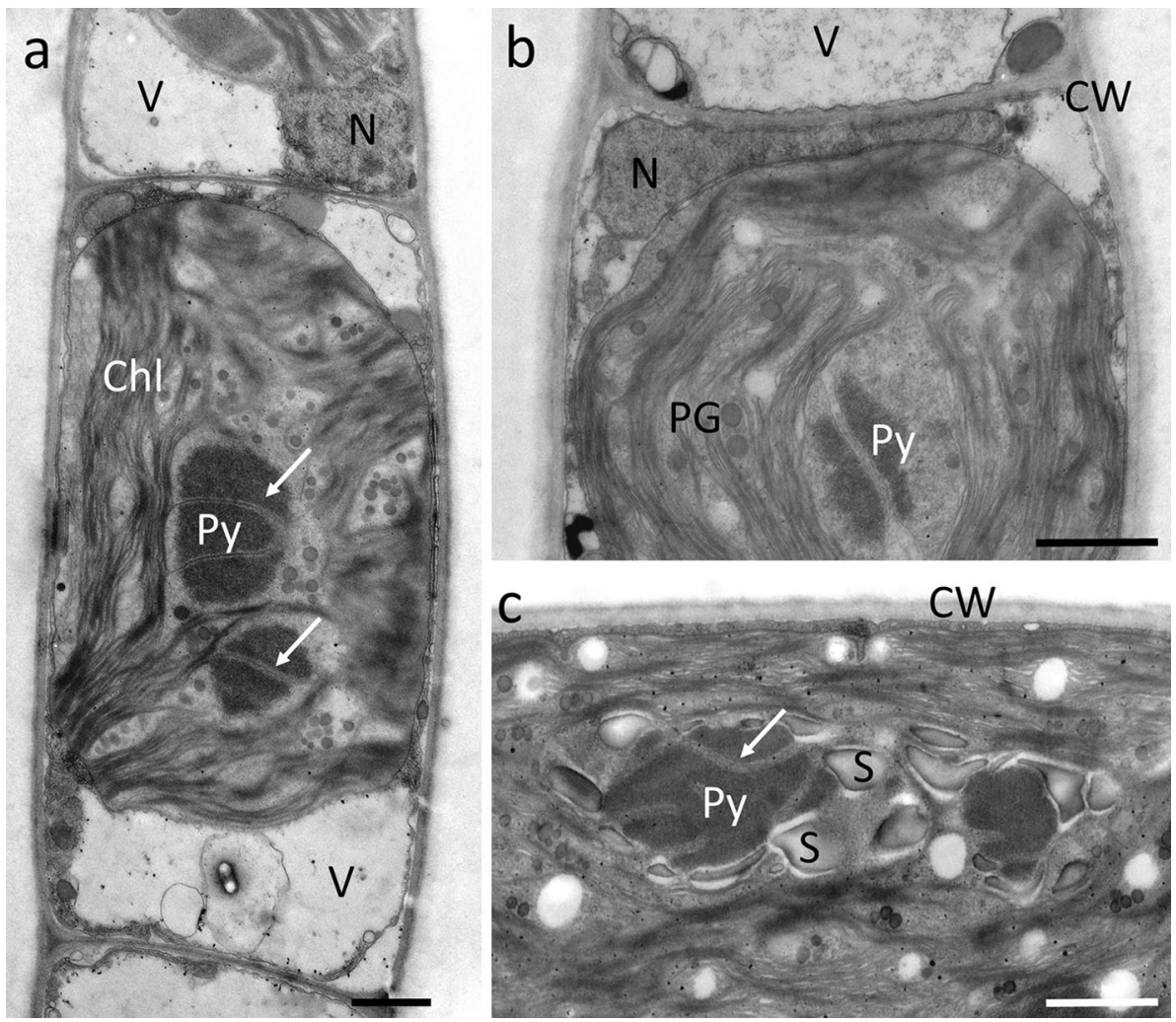
Table 1 Maximum quantum yield, dark respiration and photosynthetic characteristics ( $P$ vs $I$ curves) of the two Klebsormidium isolates and Zygnema

\begin{tabular}{lllllll}
\hline & $F_{\mathrm{v}} / F_{\mathrm{m}}$ & $R_{\mathrm{d}}^{\mathrm{a}}$ & $P_{\max }^{\mathrm{a}}$ & $\alpha^{\mathrm{b}}$ & $I_{k}^{\mathrm{c}}$ & $\beta^{\mathrm{b}}$ \\
\hline Klebsormidium sp. (SCHW) & $0.67(0.04)$ & $-29(14)$ & $197(61)$ & $7.28(2.37)$ & $30(17)$ & $-0.02(0.02)$ \\
K. cf. flaccidum (KUE1) & $0.70(0.04)$ & $-19(29)$ & $191(59)$ & $2.40(0.70)^{*}$ & $79(7)^{*}$ & $-0.00(0.01)$ \\
Zygnema sp. & $0.66(0.05)$ & $-38(15)$ & $208(54)$ & $3.15(1.84)^{*}$ & $76(22)^{*}$ & $-0.03(0.02)$ \\
\hline
\end{tabular}

Values in brackets represent standard deviation $(n \geq 3)$ and asterisks indicate statistically significant differences from Klebsormidium sp. (SCHWs)

${ }^{\mathrm{a}} \mu \mathrm{mol} \mathrm{O} \mathrm{mg} \mathrm{Chl} \mathrm{a}^{-1} \mathrm{~h}^{-1}$

b $\mu \mathrm{mol} \mathrm{O} \mathrm{O}_{2} \mathrm{mgl} \mathrm{a}^{-1}\left(\mu \mathrm{mol} \text { photons } \mathrm{m}^{-2} \mathrm{~s}^{-1}\right)^{-1}$

c $\mu \mathrm{mol}$ photons $\mathrm{m}^{-2} \mathrm{~s}^{-1}$

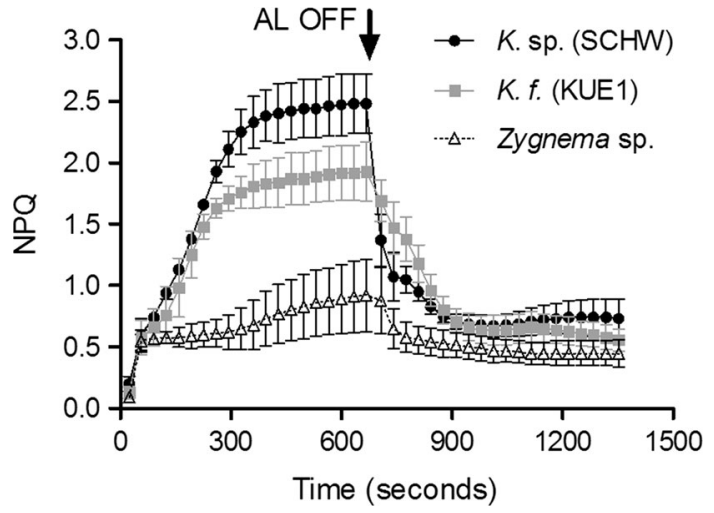

Fig. 4 Kinetics of NPQ for Klebsormidium sp. (SCHW, black circles), K. cf. flaccidum (KUE1, grey squares) and Zygnema sp. (white triangles). Arrow indicates when the actinic light (AL) was turned off. Measures were performed from at least three independent replicates

$P=0.0002$; Fig. 6b) and showing an increasing trend. Since no changes were observed in the $F_{\mathrm{m}}$ (two-way ANOVA RM, $P=0.4683$; Fig. $6 \mathrm{c}$ ), the decrease of $F_{\mathrm{o}}$ is considered the cause for the $F_{\mathrm{v}} / F_{\mathrm{m}}$ decline (two-way ANOVA RM, $P=0.0002$; data not shown). The OJIP transients measured on the same dark acclimated cells confirmed these results, showing a higher $F_{\mathrm{o}}(P=0.0109)$, unchanged $F_{\mathrm{m}} \quad(P=0.2043)$ and lower $F_{\mathrm{v}} / F_{\mathrm{m}}$ $(P=0.0029)$ in SL than in LL cells (Fig. 7; Table 2). As well as for dehydration, exposure of cells to SL influenced the recovery of the photosynthetic machinery during rehydration phase (Fig. 6d). While for the cells at LL the YII rapidly returned (within $2 \mathrm{~h}$ ) to values as high as those measured at dehydration, the YII recovery for cells in SL was slower and stopped at $\sim 73 \%$ of the YII values measured during dehydration (Fig. 6a). Consistently, after $4 \mathrm{~h}$ in rehydrated condition, cells in the SL showed lower $F_{\mathrm{v}} /$ $F_{\mathrm{m}}(0.47 \pm 0.03)$ than at LL which was fully recovered $(0.67 \pm 0.02)(P=0.0011)$, indicating the presence of PSII damages which impaired the cells to recover their photosynthetic capacity.

\section{pH-drift and $\mathrm{C}_{\mathrm{i}}$ acquisition}

The rise of $\mathrm{pH}$ during the $\mathrm{pH}$-drift experiment is shown in Fig. 8a. The pH increased rapidly from 7.6 to $\sim 9.0$ but the following increase up to final and stable values of $\sim 9.7$ occurred more slowly. The rates of $\mathrm{C}_{\mathrm{i}}$ uptake as a function of $\mathrm{C}_{\mathrm{i}}$ (Fig. 8b) did not show any species-specific variation. Similarly, the $C_{\mathrm{T}} /$ Alk quotients (Fig. 8c) were not statistically different between Klebsormidium isolates and Zygnema $(P=0.5279)$.

\section{Discussion}

In this work, we investigated the eco-physiological traits that make Klebsormidium and Zygnema capable to successfully colonize terrestrial habitats. We showed that photosynthetic characteristics are distinct between Klebsormidium and Zygnema (NPQ, photoinhibition), reflecting their preference for different light regimes in natural ecosystems. These streptophyte green algae possess comparable $\mathrm{C}_{\mathrm{i}}$ acquisition traits, indicating no genera-specific adaptation to habitats but rather an overall $\mathrm{C}_{\mathrm{i}}$ acquisition adaptation to terrestrial life. The sensitivity of Klebsormidium to light conditions during cellular water loss, emphasises the importance of considering multiple environmental factors when studying the effectiveness of mechanisms involved in protection of the photosynthetic apparatus during dehydration.

Regarding the newly isolated Klebsormidium strain from an acidic environment (Schwarzwand, Austria), the physiological comparison showed that rates of $R_{\mathrm{d}}$ and $P_{\max }$ were similar to $K$. cf. flaccidum (KUE1). This is interesting, as these two Klebsormidium strains belong to rather distinct clades according to molecular phylogeny. While by means of $r b c \mathrm{~L}$ phylogeny Klebsormidium sp. (SCHW) was grouping into clade E2, according to the terminology of Rindi et al. (2011), the $K$. cf. flaccidum strain previously 

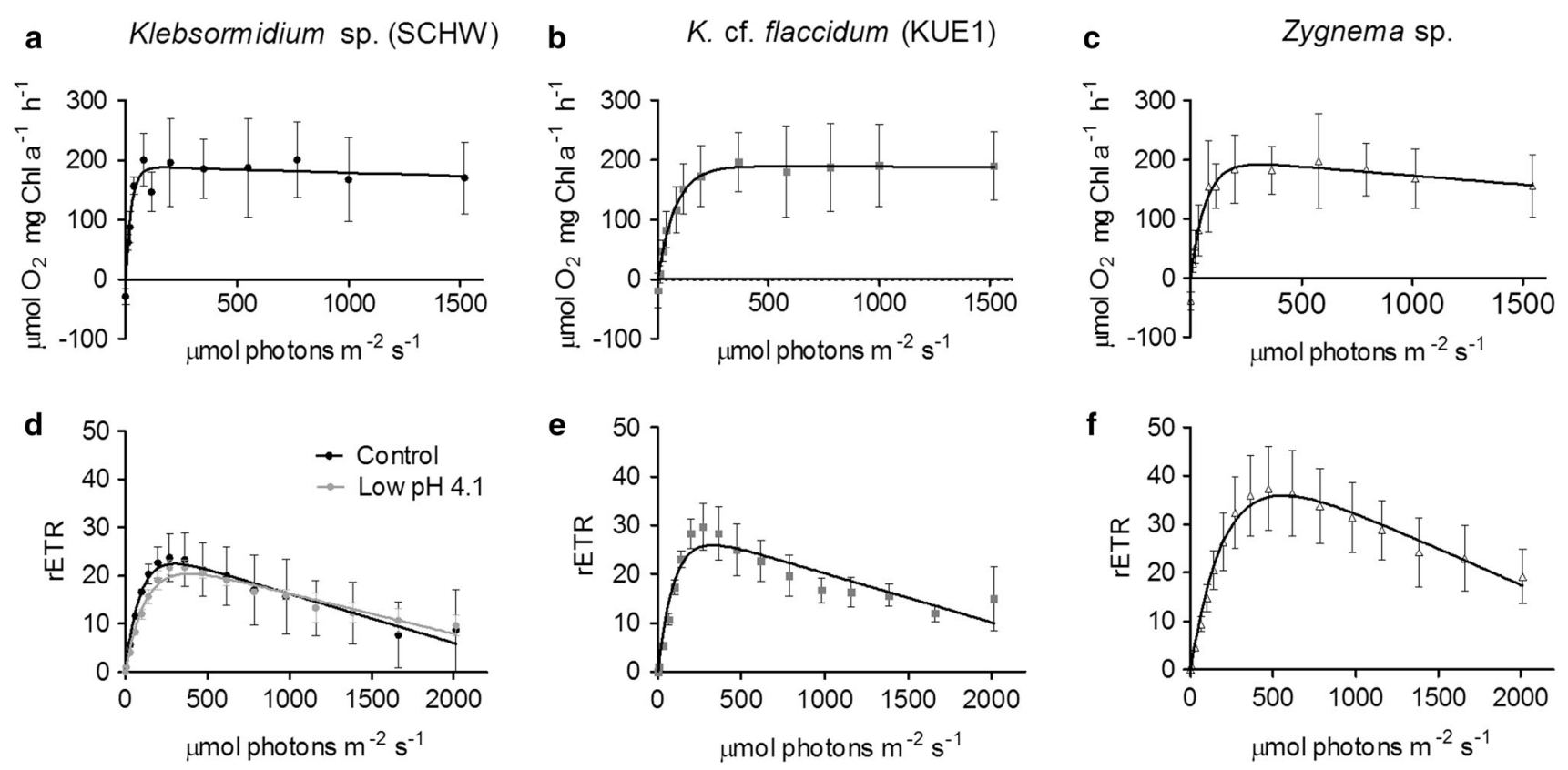

Fig. 5 Photosynthetic characteristics of Klebsormidium and Zygnema. a-c $P$ vs $I$ curves measured as an assessment of the photosynthetic responses to slow light increase. d-f RLCs used as an assessment of the photosynthetic responses to rapid increase of

isolated grouped into clade B (Karsten et al. 2013) or the combined subclades B/C (Mikhailyuk et al. 2015). However, the higher $\alpha$ in Klebsormidium sp. (SCHW) suggests a relatively higher ability to tolerate lower light and this could be attributed to the morphological differences between the two strains. In fact, the longer and tangled filaments of Klebsormidium sp. (SCHW) in comparison to $K$. cf. flaccidum (KUE1) are expected to make cells of this isolate to occur in a comparatively more self-shaded environment. The Klebsormidium sp. (SCHW) also showed negative effects on $F_{\mathrm{v}} / F_{\mathrm{m}}$ by low culture $\mathrm{pH}$, excluding the possibility that this could be a different ecotype. We, therefore, suggest that Klebsormidium occurrence in ecological niches with stressful physiological conditions (i.e., low $\mathrm{pH}$, potentially elevated heavy metal concentration) is favoured by the reduced competition with other species. Although there are indications that some Klebsormidium isolates showed preferences for certain substrata with differing pH (Ryšánek et al. 2016).

The new Klebsormidium sp. (SCHW) isolate was also characterized by light- and transmission electron microscopy, to get further insights into the subcellular organization. Prominent pyrenoids, surrounded by numerous starch grains are observed. Like for Chlamydomonas, the thylakoid membrane traversing the pyrenoid could be involved in CCM activity by containing a lumenal carbonic anhydrase which aids the conversion of $\mathrm{HCO}_{3}{ }^{-}$(transported inside the lumen from the stroma) into $\mathrm{CO}_{2}$ and light. d RLCs are included for Klebsormidium sp. (SCHW) exposed for $24 \mathrm{~h}$ at $\mathrm{pH} 4.1$. Vertical bars indicate standard deviations of at least three independent replicates

deliver $\mathrm{CO}_{2}$ in proximity to Rubisco (Moroney et al. 2011; Meyer and Griffiths 2013).

The occurrence of numerous plastoglobules in chloroplasts is usually an indication for thylakoid membrane degradation (e.g. Holzinger et al. 2011). One interesting observation was that the nuclei were frequently found in a position close to the cross cell walls. This is usually only the case after cell division (e.g., Lokhorst and Star 1985) and the nucleus moves then back to its central position. The frequent occurrence of this position either could point towards increased division activity or could be an indication of incomplete cell divisions.

For both Klebsormidium isolates and Zygnema the $I_{k}$ parameter was found to be low and very similar, suggesting a low light adaptation for these organisms (Herburger et al. 2015; Karsten et al. 2016). The presence of such low light adaptation contradicts the intuition that algae of the soil crusts (including those from high Alpine environments) may experience direct and intense solar radiation in natural conditions (Gray et al. 2007; Karsten et al. 2010). In contrast, the chlorophyte Chlorella ohadii isolated from highly irradiated desert soil crust can tolerate light intensities as high as $3500 \mu \mathrm{mol}$ photons $\mathrm{m}^{-2} \mathrm{~s}^{-1}$ (Treves et al. 2013, 2016). It has been suggested that low light adapted terrestrial species occur in micro-environments of the soil crust where they are protected from incident light, or might be relived from stressful light conditions by filaments selfshading (Gray et al. 2007; Karsten et al. 2016). A similar 

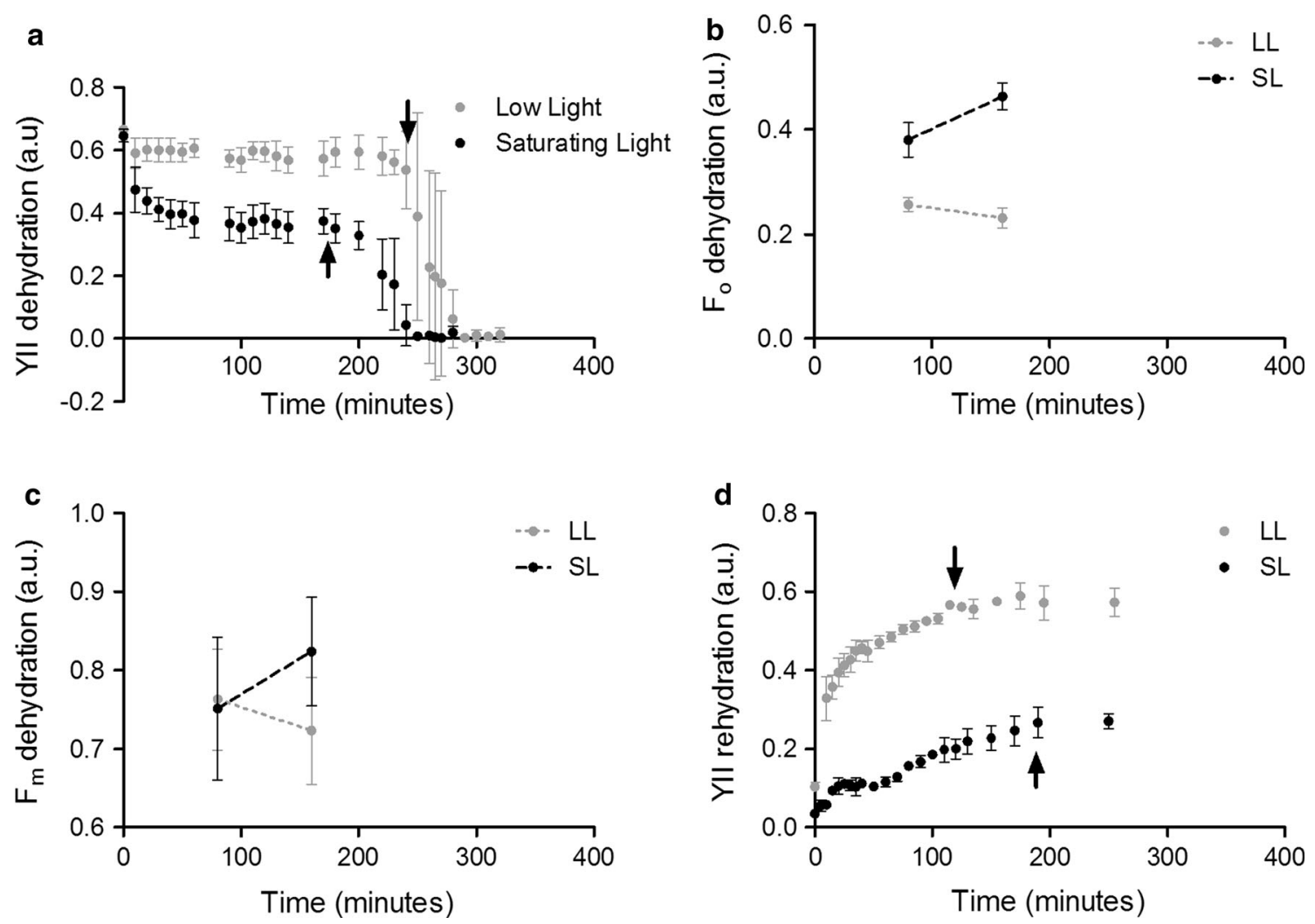

Fig. 6 Variations of fluorescence parameters for Klebsormidium sp. (SCHW) during dehydration-rehydration experiment under low light (LL, $25 \mu \mathrm{mol}$ photons $\mathrm{m}^{-2} \mathrm{~s}^{-1}$ ) and saturating light for photosynthesis (SL, $185 \mu \mathrm{mol}$ photons $\mathrm{m}^{-2} \mathrm{~s}^{-1}$ ). a YII, effective quantum yield during dehydration, with arrows pointing the time differences

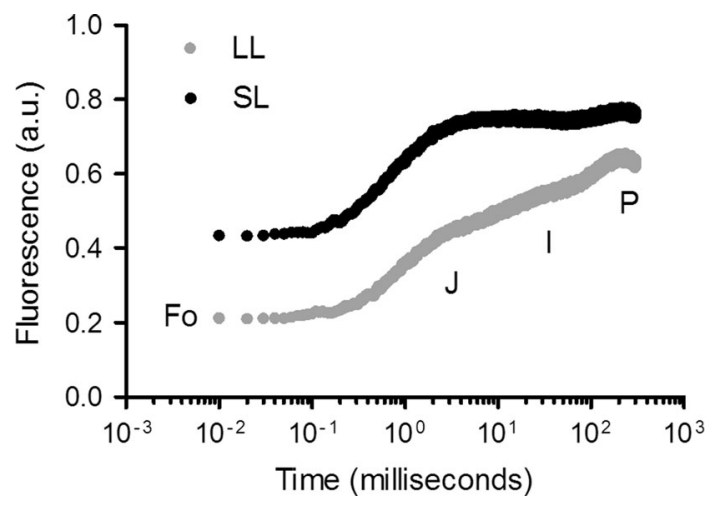

Fig. 7 O-J-I-P transients analysed on Klebsormidium sp. (SCHW) during dehydration under low light (LL, $25 \mu \mathrm{mol}$ photons $\mathrm{m}^{-2} \mathrm{~s}^{-1}$ ) and saturating light for photosynthesis (SL, $185 \mu \mathrm{mol}$ photons $\mathrm{m}^{-2} \mathrm{~s}^{-1}$ ). Results are the average of measurements performed on three independent replicates

field observation was made in a desert cyanobacterial soil crust, where maximal photosynthesis occurred beneath the surface where cells are sheltered (Raanan et al. 2016b).

Despite the similar photosynthetic light characteristics between Klebsormidium and Zygnema, drastic differences

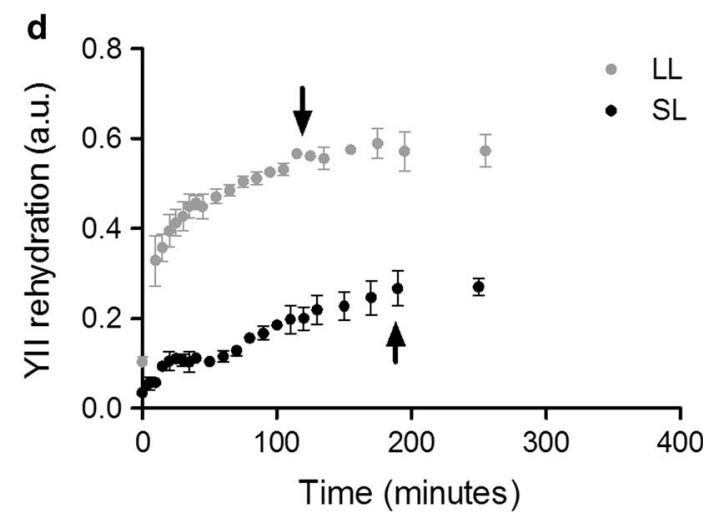

for the onset of YII decline. b $F_{\mathrm{o}}$, minimal fluorescence during dehydration. c $F_{\mathrm{m}}$, maximal fluorescence during dehydration. d Recovery of YII during rehydration (after $24 \mathrm{~h}$ of being in a dehydrated state), with arrows indicating the time when YII reaches stable values. Vertical bars indicate standard deviations of three replicates

were observed in their photoprotective mechanisms. Gerotto and Morosinotto (2013) described that for Klebsormidium and Zygnema the major component of NPQ is represented by the energy-dependent $\mathrm{qE}$, which is regulated by lumen acidification (Roach and Krieger-Liszkay 2014). For Klebsormidium the maximal NPQ was higher than in Zygnema. Moreover, for this genus the NPQ was inducible and its full capacity was reached relatively slowly during exposure to strong light, particularly in comparison to other streptophyte algae (Gerotto and Morosinotto 2013) or some aquatic microalgae (Kotabová et al. 2011; La Rocca et al. 2015). Lumen acidification and NPQ induction may also involve the presence of an active cyclic electron flow around PSI (CEF-PSI) (Golding and Johnson 2003; Joliot and Johnson 2011), and whose activity has been shown in K. flaccidum (Hori et al. 2014). Contrary to Klebsormidium, Zygnema showed a lower and a more constitutive capacity to perform NPQ. Interestingly, Zygnema differs from Klebsormidium also for not having LHCSR involved NPQ activation but PSBS protein, resembling the NPQ activation in vascular plants (Gerotto and Morosinotto 2013). However, the presence of PSBS may not be necessarily related to the closer phylogenetic 
Table 2 Parameters extrapolated from the O-J-I-P transients during Klebsormidium sp. (SCHW) dehydration ( \pm standard deviation) under low light $\left(25 \mu \mathrm{mol}\right.$ photons $\left.\mathrm{m}^{-2} \mathrm{~s}^{-1}\right)$ and saturating light for photosynthesis $\left(185 \mu \mathrm{mol}\right.$ photons $\left.\mathrm{m}^{-2} \mathrm{~s}^{-1}\right)$

\begin{tabular}{llll}
\hline OJIP parameters during dehydration & Low light & Saturating light \\
\hline$F_{\mathrm{o}}$ & Minimal fluorescence in dark & $0.22(0.06)$ & $0.44(0.06)^{*}$ \\
$F_{\mathrm{m}}$ & Maximal fluorescence in dark & $0.63(0.14)$ & $0.76(0.07)$ \\
$F_{\mathrm{v}} / F_{\mathrm{m}}$ & Maximum quantum yield & $0.66(0.06)$ & $0.43(0.03)^{*}$ \\
$V_{\mathrm{j}}$ & Fluorescence at the J-step & $0.48(0.17)$ & $0.83(0.07)^{*}$ \\
\hline
\end{tabular}

The parameter $V_{\mathrm{j}}$ was calculated according to the equation of Strasser et al. (2000). Asterisks indicate statistically significant differences from the low light treatment

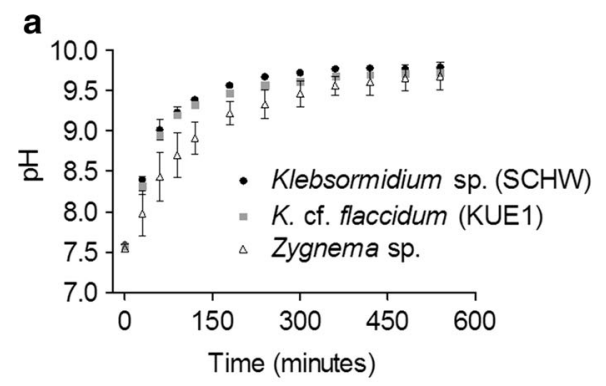

Fig. 8 a Result of pH-drift experiment carried out on Klebsormidium sp. (SCHW), K. cf. flaccidum (KUE1) and Zygnema. b Variation of $\mathrm{C}_{\mathrm{i}}$ uptake as a function of $\mathrm{C}_{\mathrm{i}}$ concentration in the assay medium. $\mathbf{c} C_{\mathrm{T}} /$

position of Zygnema to these organisms (Christa et al. 2017).

The differences in NPQ capacity and kinetics are linked the different responses of Klebsormidium and Zygnema photosynthetic apparatus to slow or rapid increase of light intensity. When the light in the environment increased relatively slow (as during $P$ vs $I$ curves), the high NPQ capacity prevented the low light adapted photosynthetic apparatus of Klebsormidium from being photoinhibited, even at light intensities as high as $1500 \mu \mathrm{mol}$ photons $\mathrm{m}^{-2} \mathrm{~s}^{-1}$. However, due to the slow NPQ activation, the photosynthetic apparatus was prone to suffer from photoinhibition if the light in the environment increases rapidly (RLC curves). During the RLCs, the activation of NPQ under strong light may also explain the inflection of the slope of photoinhibition, particularly noticeable for $K$. cf. flaccidum (KUE1). From the eco-physiological point of view, these photosynthetic responses reflect the Klebsormidium adaptation to highly irradiated terrestrial environments where increases or changes of light intensity (related to solar position in the sky or cloud cover) occur slowly during the day. For Zygnema with a much lower and not inducible NPQ capacity, the presence of photoinhibition was found under both slow and rapid increase of light. This suggests that Zygnema could prefer environments with more shaded conditions than Klebsormidium. In addition to NPQ, presence of different UV protecting compounds as
- $K . \mathrm{sp} .(\mathrm{SCHW})$

K. f. (KUE1)

Zygnema sp.
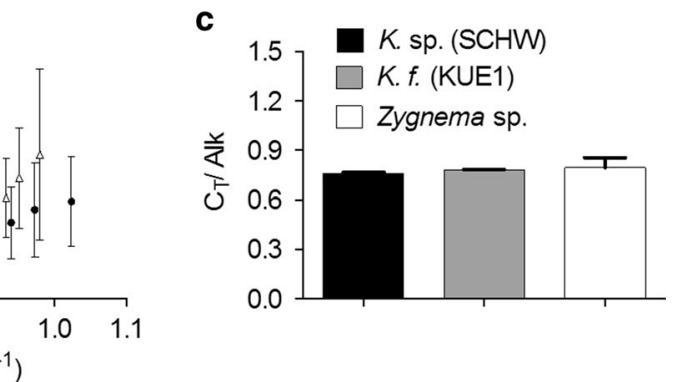

$\begin{array}{lllll}0.7 & 0.8 & 0.9 & 1.0 & 1.1 \\ & \mathrm{C}_{\mathrm{i}}\left(\mathrm{mmol} \mathrm{L}^{-1}\right)\end{array}$

Alk quotients. Vertical bars indicate the standard deviation calculated on at least three independent measures

phenolics in Zygnema (Pichrtová et al. 2013) or mycosporine-like amino acids in Klebsormidium (Kitzing et al. 2014) may further modulate the resistance under natural light conditions.

For species of the soil crust, slow increases of light intensity during mornings can also be associated with dehydration (Raanan et al. 2016a). For the young Zygnema culture investigated in the present study, we found no resistance to desiccation as previously described (Herburger et al. 2015). For Zygnema another strategy might be very important, the ability to form pre-akinetes that accumulate lipids (Pichrtová et al. 2016), and showed a reduced physiological activity, beneficial to tolerated desiccation stress (e.g., Herburger et al. 2015; Pichrtová et al. 2014). However, these pre-akinetes were not subject of the present study. In the case of the desiccation tolerant Klebsormidium, exposure to relatively high light intensity (our SL condition) during dehydration compromised the photosynthetic apparatus functioning, similarly to other terrestrial microalgae (Gray et al. 2007). Under dehydration in SL, the most noticeable change in PSII fluorescence signal was the increasing minimal $F_{\mathrm{o}}$. This result is analogous to what has been previously observed for the marine green macroalgae Ulva, where the $F_{\mathrm{o}}$ increased during, at least for the first part, the dehydration experiment (Gao et al. 2011). The authors suggested that the $F_{\mathrm{o}}$ increase is associated to a reversible inactivation of PSII reaction centres 
or the separation of the antenna complex from the PSII. However, these alterations seem not to happen at PSII level in Klebsormidium since the $F_{\mathrm{m}}$ values were not affected during dehydration. It is also known that $F_{\mathrm{o}}$ is influenced by the dark reduction of the plastoquinone (PQ) pool (Groom et al. 1993; Stirbet et al. 2014). Complementary to higher $F_{\mathrm{o}}$, the OJIP analysis revealed an increase in the $\mathrm{J}$ step $\left(V_{\mathrm{j}}\right)$ with values as high as the $\mathrm{P}$ step $\left(F_{\mathrm{m}}\right)$, and such changes have been associated to a higher reduction PQ pool (Tóth et al. 2007). We, therefore, relate the increasing $F_{\mathrm{o}}$ during dehydration in SL to an electron accumulation and a reduced state of the plastoquinone (PQ) pool along the electron transport chain (ETC). The progressive accumulation of electrons in the ETC under this condition, may eventually enhance radiative charge recombination events, leading to singlet oxygen production (Ohad et al. 2010, 2011) and thus, being responsible for the hastened PSII inactivation (YII decline) and impaired recovery after rehydration. It must also be pointed out that the SL used for this experiment is rather low $\left(185 \mu \mathrm{mol}\right.$ photons $\left.\mathrm{m}^{-2} \mathrm{~s}^{-1}\right)$ compared to full sunlight intensity of an Alpine ecosystem. We also showed that under culture (i.e., hydrated) conditions Klebsormidium can tolerate up to eightfold this level of light intensity. We suggest that the reduction of the PQ (with the consequential damages on PSII) caused by relatively high light during dehydration events is an important physiological driver which shapes the species adaptation and occurrence towards low light.

The (over) reduction of the ETC during dehydration in the SL could be linked to different physiological alterations. Holzinger et al. (2014) measured a decline in Klebsormidium $\mathrm{CO}_{2}$ consumption rate during the dehydration phase. Thus, it is highly possible that electrons could be accumulated along the ETC following an imbalance between the excitation arriving at PSII, and the ability to remove electrons from the ETC, using them for $\mathrm{CO}_{2}$ fixation (Shimakawa et al. 2017). In conjunction, alterations of mechanisms involved in the redox regulation of the PQ may also take place (Rumeau et al. 2007). It has been proposed that exposure to water loss and/or high light promotes the activity of CEF-PSI over the linear electron flow, aiding lumen acidification and inducing NPQ for PSII protection (Golding and Johnson 2003; Miyake et al. 2005; Gao et al. 2011; Meneghesso et al. 2016). Taking into consideration that a CEF-PSI (mediated through the $\mathrm{NAD}(\mathrm{P}) \mathrm{H}$ dehydrogenase complex) is possibly operative in Klebsormidium (Hori et al. 2014), it is reasonable to hypothesise that even for our Klebsormidium strain the activity CEF-PSI could be intensified under dehydration at SL, and thus contributing to PQ pool reduction.

Although Klebsormidium and Zygnema have distinguished light photosynthetic characteristics, we show that their photosynthetic $\mathrm{C}_{\mathrm{i}}$ acquisition is identical. The results of the pH-drift experiment reflected the cells ability to extract different $\mathrm{C}_{\mathrm{i}}$ forms from the water environment (Maberly and Spence 1983). The pH increase up to final values of $\sim 9.7$ suggests that Klebsormidium and Zygnema are able to uptake both $\mathrm{CO}_{2}$ and $\mathrm{HCO}_{3}{ }^{-}$for photosynthesis, and thus providing further evidence that these organisms have functional CCMs (Maberly et al. 2009). The high $C_{\mathrm{T}} /$ Alk quotients are similar to other $\mathrm{CO}_{2}$-users, as Chlamydomonas sp. and planktonic desmids (Zygnematophyceae; Spijkerman et al. 2005; Lachmann et al. 2016). This, however, could be an indication that both Klebsormidium and Zygnema have a preference for $\mathrm{CO}_{2}$. This would be particularly relevant for Klebsormidium whose occurrence is restricted to soil and aero-terrestrial environments, where $\mathrm{HCO}_{3}{ }^{-}$is not available for photosynthesis. These results do not support our hypothesis that Klebsormidium and Zygnema with different restriction to water (or isolated from acidic environment as in Lachmann et al. 2016), might possess distinguished $C_{i}$ acquisition modes. Rather, they lead to the conclusion that these organisms acquired similar adaptations of their $\mathrm{C}_{\mathrm{i}}$ acquisition during land colonization. Further studies are necessary to fully describe the terrestrial adaptation of their CCMs. Terrestrial streptophyte species are expected to be sensitive to spatial and temporal variation of $\mathrm{CO}_{2}$ in the environment. Spatially, $\mathrm{CO}_{2}$ variations could be linked to soil respiration which, stimulated by flux of organic matter, represents an input of $\mathrm{CO}_{2}$ (Suseela et al. 2012; $\mathrm{Ng}$ et al. 2014; Raven and Colmer 2016). Under the global change scenario, the long-term increase of atmospheric $\mathrm{pCO}_{2}$, predicted to reach values as high as $1000 \mathrm{ppmv}$ by the end of twenty-first century (IPCC 2014), could cause genotypic changes (Collins and Bell 2004).

In conclusion, our work demonstrated that Klebsormidium and Zygnema possess distinguished photosynthetic traits which allow them to occur under different light regimes. These physiological traits might be the consequence of several adaptations acquired during their land colonization. Terrestrial environmental conditions as high irradiation and desiccation may have been counteracting forces shaping their photosynthetic apparatus. The high light may have favoured the acquisition of photoprotective mechanisms which allow them to occur in elevated light regimes (Alboresi et al. 2008, 2010). Opposite, the alterations of the ETC (leading to PSII damages) during dehydration under illuminated conditions may have favoured a shade adaptation. This is reflected by organisms such as Klebsormidium with a low light adapted photosynthetic apparatus but tolerant to high light intensity. It is also interesting that Klebsormidium and Zygnema, from different locations, habitat preferences and evolutionary positions share a similar $\mathrm{C}_{\mathrm{i}}$ acquisition mode. It is known that atmospheric variations of $\mathrm{CO}_{2} / \mathrm{O}_{2}$ through geological 
time have given origin to diverse CCMs in aquatic algae (Raven et al. 2012, 2017; Hagemann et al. 2016). Genetic and molecular characterizations of CCMs in streptophyte algae are currently missing in the literature, although these could provide a useful insight on how atmospheric $\mathrm{CO}_{2}$ conditions have influenced land colonization by photosynthetic organisms.

Author contribution statement MP and AH designed the research and wrote the manuscript. MP conducted the physiological experiments. AH performed the light- and transmission electron microscopy. DR carried out the phylogenetic analysis. IL and WA collected and provided Klebsormidium sp. (Schwarzwand, Austria). All authors read and approved the manuscript.

Acknowledgements Open access funding provided by Austrian Science Fund (FWF). We thank the two anonymous reviewers for the constructive comments. We also kindly acknowledge technical help of Beatrix Jungwirth in cell culturing and Thomas Roach (University of Innsbruck) for useful comments provided. Sabrina Obwegeser is thanked for help in TEM sectioning. This study was supported by the Austrian Science Fund (FWF) Projects P 24242-B16 and I 1951-B16 to AH. David Ryšánek was supported by the Czech Science Foundation Grant 15-34645 L to Martina Pichrtová, Charles University, Prague, and by Charles University Science Foundation [GAUK no. 1544214].

Open Access This article is distributed under the terms of the Creative Commons Attribution 4.0 International License (http://crea tivecommons.org/licenses/by/4.0/), which permits unrestricted use, distribution, and reproduction in any medium, provided you give appropriate credit to the original author(s) and the source, provide a link to the Creative Commons license, and indicate if changes were made.

\section{References}

Adlassnig W, Sassmann S, Lendl T, Wernitznig S, Hofhansl F, Lang I, Lichtscheidl IK (2013) Metal contamination and retention of the former mining site Schwarzwand (Salzburg, Austria). Appl Geochem 35:196-206

Alboresi A, Caffarri S, Nogue F, Bassi R, Morosinotto T (2008) In silico and biochemical analysis of Physcomitrella patens photosynthetic antenna: identification of subunits which evolved upon land adaptation. PLoS One 3:e2033

Alboresi A, Gerotto C, Giacometti GM, Bassi R, Morosinotto T (2010) Physcomitrella patens mutants affected on heat dissipation clarify the evolution of photoprotection mechanisms upon land colonization. Proc Natl Acad Sci USA 107:11128-11133

Bar-Eyal L, Eisenberg I, Faust A, Raanan H, Nevo R, Rappaport F, Krieger-Liszkay A, Sétif P, Thurotte A, Reich Z, Kaplan A, Ohad I, Paltiel Y, Keren N (2015) An easily reversible structural change underlies mechanisms enabling desert crust cyanobacteria to survive desiccation. Biochim Biophys Acta 1847:1267-1273

Becker B (2013) Snow ball earth and the split of Streptophyta and Chlorophyta. Trends Plant Sci 18:180-183

Becker B, Marin B (2009) Streptophyte algae and the origin of embryophytes. Ann Bot 103:999-1004
Birmingham BC, Colman B (1979) Measurement of carbon dioxide compensation points of freshwater algae. Plant Physiol 64:892-895

Brading P, Warner ME, Smith DJ, Suggett DJ (2013) Contrasting modes of inorganic carbon acquisition amongst Symbiodinium (Dinophyceae) phylotypes. New Phytol 200:432-442

Christa G, Cruz S, Jahns P, de Vries J, Cartaxana P, Esteves AC, Serôdio J, Gould SB (2017) Photoprotection in a monophyletic branch of chlorophyte algae is independent of energy-dependent quenching (qE). New Phytol 214:1132-1144

Collins S, Bell G (2004) Phenotypic consequences of 1000 generations of selection at elevated $\mathrm{CO}_{2}$ in a green alga. Nature 431:566-569

Cruz de Carvalho R, Bernardes da Silva A, Soares R, Almeida AM, Coelho AV, Marques da Silva J, Branquinho C (2014) Differential proteomics of dehydration and rehydration in bryophytes: evidence towards a common desiccation tolerance mechanism. Plant Cell Environ 37:1499-1515

de Vries J, Stanton A, Archibald JM, Gould SB (2016) Streptophyte terrestrialization in light of plastid evolution. Trends Plant Sci $21: 467-476$

de Vries J, de Vries S, Slamovits CH, Rose LE, Archibald JM (2017) How embryophytic is the biosynthesis of phenylpropanoids and their derivatives in streptophyte algae? Plant Cell Physiol 58:934-945

Elbert W, Weber B, Burrows S, Steinkamp J, Büdel B, Andreae MO, Pöschl U (2012) Contribution of cryptogamic covers to the global cycles of carbon and nitrogen. Nat Geosci 5:459-462

Gao S, Shen S, Wang G, Niu J, Lin A, Pan G (2011) PSI-driven cyclic electron flow allows intertidal macro-algae Ulva sp. (Chlorophyta) to survive in desiccated conditions. Plant Cell Physiol 52:885-893

Gerloff-Elias A, Spijkerman E, Pröschold T (2005) Effect of external $\mathrm{pH}$ on the growth, photosynthesis and photosynthetic electron transport of Chlamydomonas acidophila Negoro, isolated from an extremely acidic lake $(\mathrm{pH}$ 2.6). Plant Cell Environ 28:1218-1229

Gerotto C, Morosinotto T (2013) Evolution of photoprotection mechanisms upon land colonization: evidence of PSBS-dependent NPQ in late Streptophyte algae. Physiol Plant 149:583-598

Gerotto C, Alboresi A, Giacometti GM, Bassi R, Morosinotto T (2011) Role of PSBS and LHCSR in Physcomitrella patens acclimation to high light and low temperature. Plant Cell Environ 34:922-932

Giordano M, Beardall J, Raven JA (2005) $\mathrm{CO}_{2}$ concentrating mechanisms in algae: mechanisms, environmental modulation, and evolution. Annu Rev Plant Biol 56:99-131

Golding AJ, Johnson GN (2003) Down-regulation of linear and activation of cyclic electron transport during drought. Planta 218:107-114

Goss R, Lepetit B (2015) Biodiversity of NPQ. J Plant Physiol 172:13-32

Gray DW, Lewis LA, Cardon ZG (2007) Photosynthetic recovery following desiccation of desert green algae (Chlorophyta) and their aquatic relatives. Plant Cell Environ 30:1240-1255

Groom QJ, Kramer DM, Crofts AR, Ort DR (1993) The nonphotochemical reduction of plastoquinone in leaves. Photosynth Res 36:205-215

Hagemann M, Kern R, Maurino VG, Hanson DT, Weber AP, Sage RF, Bauwe H (2016) Evolution of photorespiration from cyanobacteria to land plants, considering protein phylogenies and acquisition of carbon concentrating mechanisms. J Exp Bot 67:2963-2976

Heber U (2008) Photoprotection of green plants: a mechanism of ultra-fast thermal energy dissipation in desiccated lichens. Planta 228:641-650 
Hepperle D (2004) SeqAssem $\odot$. A sequence analysis tool, contig assembler and trace data visualisation tool for molecular sequences, version 09/2004. http://www.sequentix.de

Herburger K, Holzinger A (2015) Localization and quantification of callose in the streptophyte green algae Zygnema and Klebsormidium: correlation with desiccation tolerance. Plant Cell Physiol 56:2259-2270

Herburger K, Lewis LA, Holzinger A (2015) Photosynthetic efficiency, desiccation tolerance and ultrastructure in two phylogenetically distinct strains of alpine Zygnema sp. (Zygnematophyceae, Streptophyta): role of pre-akinete formation. Protoplasma 252:571-589

Holland DP, Pantorno A, Orr PT, Stojkovic S, Beardall J (2012) The impacts of a high $\mathrm{CO}_{2}$ environment on a bicarbonate user: the cyanobacterium Cylindrospermopsis raciborskii. Water Res 46:1430-1437

Holzinger A, Karsten U (2013) Desiccation stress and tolerance in green algae: consequences for ultrastructure, physiological and molecular mechanisms. Front Plant Sci 4:327

Holzinger A, Pichrtová M (2016) Abiotic stress tolerance of charophyte green algae: new challenges for omics techniques. Front Plant Sci 7:678

Holzinger A, Roleda MY, Lütz C (2009) The vegetative arctic freshwater green alga Zygnema is insensitive to experimental UV exposure. Micron 40:831-838

Holzinger A, Lütz C, Karsten U (2011) Desiccation stress causes structural and ultrastructural alterations in the aeroterrestrial green alga Klebsormidium crenulatum (Klebsormidiophyceae, Streptophyta) isolated from an alpine soil crust1. J Phycol 47:591-602

Holzinger A, Kaplan F, Blaas K, Zechmann B, Komsic-Buchmann K, Becker B (2014) Transcriptomics of desiccation tolerance in the streptophyte green alga Klebsormidium reveal a land plant-like defense reaction. PLoS One 9:e110630

Hori K, Maruyama F, Fujisawa T et al (2014) Klebsormidium flaccidum genome reveals primary factors for plant terrestrial adaptation. Nat Commun 5:3978

Huelsenbeck JP, Ronquist F (2001) MRBAYES: bayesian inference of phylogenetic trees. Bioinformatics 17:754-755

IPCC (2014) Climate change 2014: synthesis report. In: Core Writing Team, Pachauri RK, Meyer LA (eds) Contribution of Working Groups I, II and III to the Fifth assessment report of the intergovernmental panel on climate change. IPCC, Geneva, Switzerland

Joliot P, Johnson GN (2011) Regulation of cyclic and linear electron flow in higher plants. Proc Natl Acad Sci USA 108:13317-13322

Kaplan F, Lewis LA, Herburger K, Holzinger A (2013) Osmotic stress in Arctic and Antarctic strains of the green alga Zygnema (Zygnematales, Streptophyta): effects on photosynthesis and ultrastructure. Micron 44:317-330

Karsten U, Holzinger A (2014) Green algae in alpine biological soil crust communities: acclimation strategies against ultraviolet radiation and dehydration. Biodivers Conserv 23:1845-1858

Karsten U, Lütz C, Holzinger A (2010) Ecophysiological performance of the aeroterrestrial green alga Klebsormidium crenulatum (Charophyceae, Streptophyta) isolated from an alpine soil crust with an emphasis on desiccation stress. J Phycol 46:1187-1197

Karsten U, Pröschold T, Mikhailyuk T, Holzinger A (2013) Photosynthetic performance of different genotypes of the green alga Klebsormidium sp. (Streptophyta) isolated from biological soil crusts of the Alps. Algol Stud 142:45-62

Karsten U, Herburger K, Holzinger A (2014) Dehydration, temperature, and light tolerance in members of the aeroterrestrial green algal genus Interfilum (Streptophyta) from biogeographically different temperate soils. J Phycol 50:804-816
Karsten U, Herburger K, Holzinger A (2016) Living in biological soil crust communities of African deserts-physiological traits of green algal Klebsormidium species (Streptophyta) to cope with desiccation, light and temperature gradients. J Plant Physiol 194:2-12

Kitzing C, Pröschold T, Karsten U (2014) UV-induced effects on growth, photosynthetic performance and sunscreen contents in different populations of the green alga Klebsormidium fluitans (Streptophyta) from alpine soil crusts. Microbial Ecol 67:327-340

Kotabová E, Kaňa R, Jarešová J, Prášil O (2011) Non-photochemical fluorescence quenching in Chromera velia is enabled by fast violaxanthin de-epoxidation. FEBS Lett 585:1941-1945

La Rocca N, Sciuto K, Meneghesso A, Moro I, Rascio N, Morosinotto $\mathrm{T}$ (2015) Photosynthesis in extreme environments: responses to different light regimes in the Antarctic alga Koliella antarctica. Physiol Plant 153:654-667

Lachmann SC, Maberly SC, Spijkerman E (2016) Ecophysiology matters: linking inorganic carbon acquisition to ecological preference in four species of microalgae (Chlorophyceae). J Phycol 52:1051-1063

Lajos K, Mayr S, Buchner O, Blaas K, Holzinger A (2016) A new microscopic method to analyse desiccation-induced volume changes in aeroterrestrial green algae. J Microsc 263:192-199

Leliaert F, Verbruggen H, Zechman FW (2011) Into the deep: new discoveries at the base of the green plant phylogeny. Bioessays 33:683-692

Lokhorst GM, Star W (1985) Ultrastructure of mitosis and cytokinesis in Klebsormidium mucosum nov. comb., formerly Ulothrix verrucosa (Chlorophyta). J Phycol 21:466-476

Maberly SC, Spence DHN (1983) Photosynthetic inorganic carbon use by freshwater plants. J Ecol 71:705-724

Maberly SC, Ball LA, Raven JA, Sültemeyer D (2009) Inorganic carbon acquisition by chrysophytes. J Phycol 45:1052-1061

Meneghesso A, Simionato D, Gerotto C, La Rocca N, Finazzi G, Morosinotto T (2016) Photoacclimation of photosynthesis in the Eustigmatophycean Nannochloropsis gaditana. Photosynth Res 129:291-305

Meyer M, Griffiths $\mathrm{H}$ (2013) Origins and diversity of eukaryotic $\mathrm{CO}_{2^{-}}$ concentrating mechanisms: lessons for the future. J Exp Bot 64:769-786

Meyer M, Seibt U, Griffiths H (2008) To concentrate or ventilate? Carbon acquisition, isotope discrimination and physiological ecology of early land plant life forms. Philos Trans R Soc Lond B Biol Sci 363:2767-2778

Mikhailyuk T, Glaser K, Holzinger A, Karsten U (2015) Biodiversity of Klebsormidium (Streptophyta) from alpine biological soil crusts (Alps, Tyrol, Austria, and Italy). J Phycol 51:750-767

Millero FJ (1979) The thermodynamics of the carbonate system in seawater. Geochim Cosmochim Acta 43:1651-1661

Miyake C, Horiguchi S, Makino A, Shinzaki Y, Yamamoto H, Tomizawa KI (2005) Effects of light intensity on cyclic electron flow around PSI and its relationship to non-photochemical quenching of $\mathrm{Chl}$ fluorescence in tobacco leaves. Plant Cell Physiol 46:1819-1830

Moroney JV, Ma Y, Frey WD, Fusilier KA, Pham TT, Simms TA, DiMario RJ, Yang J, Mukherjee B (2011) The carbonic anhydrase isoforms of Chlamydomonas reinhardtii: intracellular location, expression, and physiological roles. Photosynth Res 109:133-149

Ng EL, Patti AF, Rose MT, Schefe CR, Wilkinson K, Smernik RJ, Cavagnaro TR (2014) Does the chemical nature of soil carbon drive the structure and functioning of soil microbial communities? Soil Biol Biochem 70:54-61

Ohad I, Raanan H, Keren N, Tchernov D, Kaplan A (2010) Lightinduced changes within photosystem II protects Microcoleus sp. 
in biological desert sand crusts against excess light. PLoS One 5:e11000

Ohad I, Berg A, Berkowicz SM, Kaplan A, Keren N (2011) Photoinactivation of photosystem II: is there more than one way to skin a cat? Physiol Plant 142:79-86

Pichrtová M, Remias D, Lewis LA, Holzinger A (2013) Changes in phenolic compounds and cellular ultrastructure of Arctic and Antarctic strains of Zygnema (Zygnematophyceae, Streptophyta) after exposure to experimentally enhanced UV to PAR ratio. Microbial Ecol 65:68-83

Pichrtová M, Kulichová J, Holzinger A (2014) Nitrogen limitation and slow drying induce desiccation tolerance in conjugating green algae (Zygnematophyceae) from polar habitats. PLoS One 9:e113137

Pichrtová M, Arc E, Stöggl W, Kranner I, Hajek T, Hackl H, Holzinger A (2016) Formation of lipid bodies and changes in fatty acid composition upon pre-akinete formation in arctic and Antarctic Zygnema (Zygnematophyceae, Streptophyta) strains. FEMS Microbiol Ecol 92:fiw096

Pierangelini M, Stojkovic S, Orr PT, Beardall J (2014) Elevated $\mathrm{CO}_{2}$ causes changes in the photosynthetic apparatus of a toxic cyanobacterium, Cylindrospermopsis raciborskii. J Plant Physiol 171:1091-1098

Porra RJ, Thompson WA, Kriedemann PE (1989) Determination of accurate extinction coefficients and simultaneous equations for assaying chlorophylls $a$ and $b$ extracted with four different solvents: verification of the concentration of chlorophyll standards by atomic absorption spectroscopy. BBA Bioenerg 975:384-394

Raanan H, Felde VJ, Peth S, Drahorad S, Ionescu D, Eshkol G, Treves $\mathrm{H}$, Felix-Henningsen P, Berkowicz SM, Keren N, Horn R, Hagemann M, Kaplan A (2016a) Three-dimensional structure and cyanobacterial activity within a desert biological soil crust. Environ Microbiol 18:372-383

Raanan H, Oren N, Treves H, Berkowicz SM, Hagemann M, Pade N, Keren N, Kaplan A (2016b) Simulated soil crust conditions in a chamber system provide new insights on cyanobacterial acclimation to desiccation. Environ Microbiol 18:414-426

Ratti S, Giordano M, Morse D (2007) $\mathrm{CO}_{2}$-concentrating mechanisms of the potentially toxic dinoflagellate Protoceratium reticulatum (Dinophyceae, Gonyaulacales). J Phycol 43:693-701

Raven JA, Colmer TD (2016) Life at the boundary: photosynthesis at the soil-fluid interface. A synthesis focusing on mosses. J Exp Bot 67:1613-1623

Raven JA, Giordano M, Beardall J, Maberly SC (2012) Algal evolution in relation to atmospheric $\mathrm{CO}_{2}$ : carboxylases, carbonconcentrating mechanisms and carbon oxidation cycles. Philos Trans R Soc B 367:493-507

Raven JA, Beardall J, Sánchez-Baracaldo P (2017) The possible evolution, and future, of $\mathrm{CO}_{2}$-concentrating mechanisms. J Exp Bot. doi:10.1093/jxb/erx110 (in press)

Reinfelder JR (2011) Carbon concentrating mechanisms in eukaryotic marine phytoplankton. Annu Rev Mar Sci 3:291-315

Rindi F, Mikhailyuk TI, Sluiman HJ, Friedl T, López-Bautista JM (2011) Phylogenetic relationships in Interfilum and Klebsormidium (Klebsormidiophyceae, Streptophyta). Mol Phylogenet Evol 58:218-231

Roach T, Krieger-Liszkay A (2014) Regulation of photosynthetic electron transport and photoinhibition. Curr Protein Pept Sci 15:351-362

Rumeau D, Peltier G, Cournac L (2007) Chlororespiration and cyclic electron flow around PSI during photosynthesis and plant stress response. Plant Cell Environ 30:1041-1051

Ryšánek D, Hrčková K, Škaloud P (2015) Global ubiquity and local endemism of free-living terrestrial protists: phylogeographic assessment of the streptophyte alga Klebsormidium. Environ Microbiol 17:689-698

Ryšánek D, Holzinger A, Škaloud P (2016) Influence of substrate and $\mathrm{pH}$ on diversity of the aeroterrestrial alga Klebsormidium: a potentially important factor for sympatric speciation? Phycologia 55:347-358

Shimakawa G, Matsuda Y, Nakajima K, Tamoi M, Shigeoka S, Miyake C (2017) Diverse strategies of $\mathrm{O}_{2}$ usage for preventing photo-oxidative damage under $\mathrm{CO}_{2}$ limitation during algal photosynthesis. Sci Rep 7:41022

Škaloud P, Rindi F (2013) Ecological differentiation of cryptic species within an asexual protist morphospecies: a case study of filamentous green alga Klebsormidium (Streptophyta). J Eukaryot Microbiol 60:350-362

Smith EC, Griffiths H (1996) The occurrence of the chloroplast pyrenoid is correlated with the activity of a $\mathrm{CO}_{2}$-concentrating mechanism and carbon isotope discrimination in lichens and bryophytes. Planta 198:6-16

Spijkerman E, Maberly SC, Coesel PF (2005) Carbon acquisition mechanisms by planktonic desmids and their link to ecological distribution. Can J Bot 83:850-858

Stirbet A, Riznichenko GY, Rubin AB, Govindjee (2014) Modeling chlorophyll $a$ fluorescence transient: relation to photosynthesis. Biochemistry (Moscow) 79:291-323

Stojkovic S, Beardall J, Matear R (2013) $\mathrm{CO}_{2}$-concentrating mechanisms in three southern hemisphere strains of Emiliania huxleyi. J Phycol 49:670-679

Strasser RJ, Srivastava A, Tsimilli-Michael M (2000) The fluorescence transient as a tool to characterize and screen photosynthetic samples. In: Yunuf M, Pathre M, Mohanty P (eds) Probing photosynthesis: mechanisms, regulation and adaptation. CRC Press, Boca Raton, pp 445-483

Suseela V, Conant RT, Wallenstein MD, Dukes JS (2012) Effects of soil moisture on the temperature sensitivity of heterotrophic respiration vary seasonally in an old-field climate change experiment. Glob Change Biol 18:336-348

Swofford DL (2002) PAUP*: phylogenetic analysis using parsimony (*and other methods). Version 4. Sinauer Associates, Sunderland

Tamura K, Peterson D, Peterson N, Stecher G, Nei M, Kumar S (2011) MEGA5: molecular evolutionary genetics analysis using maximum likelihood, evolutionary distance, and maximum parsimony methods. Mol Biol Evol 28:2731-2739

Thompson JD, Higgins DG, Gibson TJ (1994) CLUSTAL W: improving sensitivity of progressive multiple sequence alignment through sequence weighting, position 86 specific gap penalties, and weight matrix choice. Nuc Acid Res 22:4673-4680

Timme RE, Bachvaroff TR, Delwiche CF (2012) Broad phylogenomic sampling and the sister lineage of land plants. PLoS One 7:e29696

Tóth SZ, Schansker G, Strasser RJ (2007) A non-invasive assay of the plastoquinone pool redox state based on the OJIP-transient. Photosynth Res 93:193-203

Treves H, Raanan H, Finkel OM, Berkowicz SM, Keren N, Shotland Y, Kaplan A (2013) A newly isolated Chlorella sp. from desert sand crusts exhibits a unique resistance to excess light intensity. FEMS Microbiol Ecol 86:373-380

Treves H, Raanan H, Kedem I, Murik O, Keren N, Zer H, Berkowicz SM, Giordano M, Norici A, Shotland Y, Ohad I, Kaplan A (2016) The mechanisms whereby the green alga Chlorella ohadii, isolated from desert soil crust, exhibits unparalleled photodamage resistance. New Phytol 210:1229-1243

Villarreal JC, Renner SS (2012) Hornwort pyrenoids, carbonconcentrating structures, evolved and were lost at least five times during the last 100 million years. Proc Natl Acad Sci 109:18873-18878 
Walsby AE (1997) Numerical integration of phytoplankton photosynthesis through time and depth in a water column. New Phytol 136:189-209

Yamakawa H, Fukushima Y, Itoh S, Heber U (2012) Three different mechanisms of energy dissipation of a desiccation-tolerant moss serve one common purpose: to protect reaction centres against photo-oxidation. J Exp Bot 63:1-11
Zwickl DJ (2006) Genetic algorithm approaches for the phylogenetic analysis of large biological sequence datasets under the maximum likelihood criterion. Dissertation, University of Texas at Austin 